\title{
Caracterização mineralógica e química dos regolitos de uma área de transição savana-floresta em Roraima: uma análise da evolução da paisagem
}

\author{
Maria Ecilene Nunes da Silva Meneses ${ }^{1 *}$, Marcondes Lima da Costa ${ }^{1}$
}

\begin{abstract}
Resumo O presente estudo foi realizado em uma área de transição savana-floresta do norte do estado de Roraima, tendo como objetivo principal caracterizar os regolitos dispostos ao longo da paisagem e inferir sobre a evolução da paisagem durante o Holoceno tardio e mesmo no presente. Assim, foram selecionadas quatro topossequências representativas dos padrões geomorfológicos, pedológicos e botânicos ocorrentes na paisagem, ao longo das quais foram coletadas sistematicamente amostras de solos e sedimentos. Essas amostras foram analisadas quanto às suas características granulométricas, mineralógicas, químicas e cronológicas. Os resultados revelaram uma paisagem dominada por solos arenosos a sílticos constituídos essencialmente de quartzo e caulinita e acessoriamente muscovita, goethita, sillimanita e albita. Os altos teores elevados de $\mathrm{SiO}_{2}$ confirmam o caráter essencialmente quartzoso desses regolitos. As composições mineralógicas e químicas desses materiais indicam proveniência de rochas metamórficas e de lateritos da região que, diante das condições climáticas quentes e úmidas preponderantes durante os últimos 1550 anos antes do presente (AP), tem sofrido intenso intemperismo químico e lixiviação. A evolução da paisagem é dinamizada pela erosão hídrica das encostas e o consequente assoreamento dos vales de veredas, levando ao aplainamento da paisagem e desenvolvimento de extensas planícies arenosas a partir dos solos areno-sílticos dos interflúvios.
\end{abstract}

Palavras-chave: evolução da paisagem; Holoceno tardio; mineralogia e química dos regolitos; área de transição savanafloresta; Roraima.

\begin{abstract}
Mineralogical and chemistry characterization of regolith from an area of savanna-forest transition in Roraima: an analysis of the evolution of the landscape. The present study was carried out in an area of transition savannaforest of the north of Roraima state. The main objective was to characterize the landscape regoliths and evaluate the evolution of the landscape during the late Holocene and even the present-day. Thus, four topossequences representative of the geomorphological, pedological and botanical patterns along the regional landscape were selected to sampling of soils and sediments. These samples were analyzed as for their granulometrical, mineralogical, chemical and chronological characteristics. The results revealed a landscape dominated by sandy to silty soils constituted essentially of quartz and kaolinit, besides muscovite, goethite, sillimanite and albite in low amounts. The high values of $\mathrm{SiO}_{2}$ confirm the quartzic character of these regoliths. The mineralogical and chemical compositions of these materials indicate provenience of metamorphic rocks and of laterites of the area, which due to the dominant warm and humid climatic conditions during the last 1550 years before the present, has been suffering intense chemical weathering and leaching. The landscape evolution is controlled by hidrological erosion of the hillsides and the filling of the valleys of 'veredas' causing the leveling of the landscape and the development of extensive sandy plains from the interfluves soils.
\end{abstract}

Keywords: evolution of the landscape; late Holocene; mineralogy and chemistry of the regoliths; savanna-forest transition area; Roraima.

\section{INTRODUÇ̃̃o A ocorrência de extensas sa-} vanas em muitos locais da região amazônica tem levado à realização de diversos estudos que buscam, sobretudo, entender como paisagens tão diversas podem ocorrer em meio a um domínio de floresta tropical típica. A origem das savanas amazônicas é ainda debatida e, assim, creditada a vários fatores, entre eles a pobreza e deficiência hídrica dos solos e a atuação do fogo natural ou antrópico. No entanto, a hipótese mais difundida segue a teoria dos refúgios, segundo a qual, a Amazônia era dominada por savanas, com ilhas de floresta úmida durante as glaciações do Pleistoceno, e que com o retorno da umidade no Holoceno, essas ilhas de floresta teriam novamente se expandido e isolado as savanas (Absy et al. 1991, Desjardins et al. 1996, Behling \& Hooghiemstra 1998, 2000, Mayle et al. 2007). De acordo com esses estudos, as savanas atuais da região amazônica são relíquias das antigas formações abertas que dominaram grande parte do norte da América do Sul. Todavia, o modelo dos refúgios tem sido refutado por diversos autores (Bush et al. 2004, Colinvaux et al. 1996) que pregam a estabilidade e continuidade 
da floresta tropical úmida durante o Quaternário, e assim argumentam contra a existência de ciclos climáticos secos que possam ter gerado sua fragmentação. Atualmente, um dos maiores blocos de savanas da América do Sul ocorre nas porções norte e nordeste do estado de Roraima, adentra terras da República da Guiana, e com cerca de $53.000 \mathrm{~km}^{2}\left(41.000 \mathrm{~km}^{2}\right.$ somente em Roraima), se estende até os limites do rio Rupununi e, por isso, denominado de Complexo Rio Branco-Rupununi (Sarmiento \& Monasterio 1975). Entre os habitantes locais, a região é conhecida como "lavrado", termo que significa paisagem desprovida de árvores (Vanzolini \& Carvalho 1991).

Além da cobertura vegetal, as diferentes feições pedogeomórficas, tais como campos de paleodunas, planícies lacustres, coberturas lateríticas e linhas de pedra, que podem ser entendidos como regolitos, encontradas ao longo dessa região, motivaram diversos estudos (Schaefer \& Dalrymple 1996, Carneiro Filho 1991), que através de dados palinológicos, químicos e sedimentológicos tentam reconstituir paleoambientes e suas respectivas condições climáticas. A maioria dos dados disponíveis para a região de savanas de Roraima diz respeito à parte leste do bloco a exemplo do lago Caracaranã estudado por Simões Filho (2000) e arredores da capital Boa Vista (Absy et al. 1997), que corresponde à zona mais seca da região, onde as savanas são amplamente dominantes.

No presente estudo, o foco está voltado para a área de transição entre as savanas e a floresta, caracterizada por um emaranhado complexo de savanas graminosas e arbóreas, ilhas e corredores de florestas e veredas de buritis. Destacam-se, também, nessa paisagem, inúmeros corpos lacustres, campos arenosos, coberturas e remanescentes lateríticos e perfis de solos truncados por linhas de pedra, que conferem à mesma uma extraordinária heterogeneidade em contraposição a ideia de monotonia normalmente atribuída. O objetivo do presente trabalho é identificar a interação entre os vários regolitos que constituem a paisagem através de suas características granulométricas, mineralógicas e químicas durante o Holoceno tardio e ainda a sua dinâmica frente às atuais condições climáticas.

ASPECTOS FISIOGRÁFICOS REGIONAIS A área de estudo está localizada na porção norte do estado de Roraima, entre as coordenadas $3^{\circ} 20^{\prime} 10^{\prime \prime} \mathrm{e}$ $3^{\circ} 42^{\prime} \mathrm{N}$, e $61^{\circ} 12^{\prime} 00^{\prime}$ ' e $61^{\circ} 34^{\prime} 05^{\prime}$ ' W, que envolve uma área de transição entre savana e floresta tropical amazônica (Fig. 1).

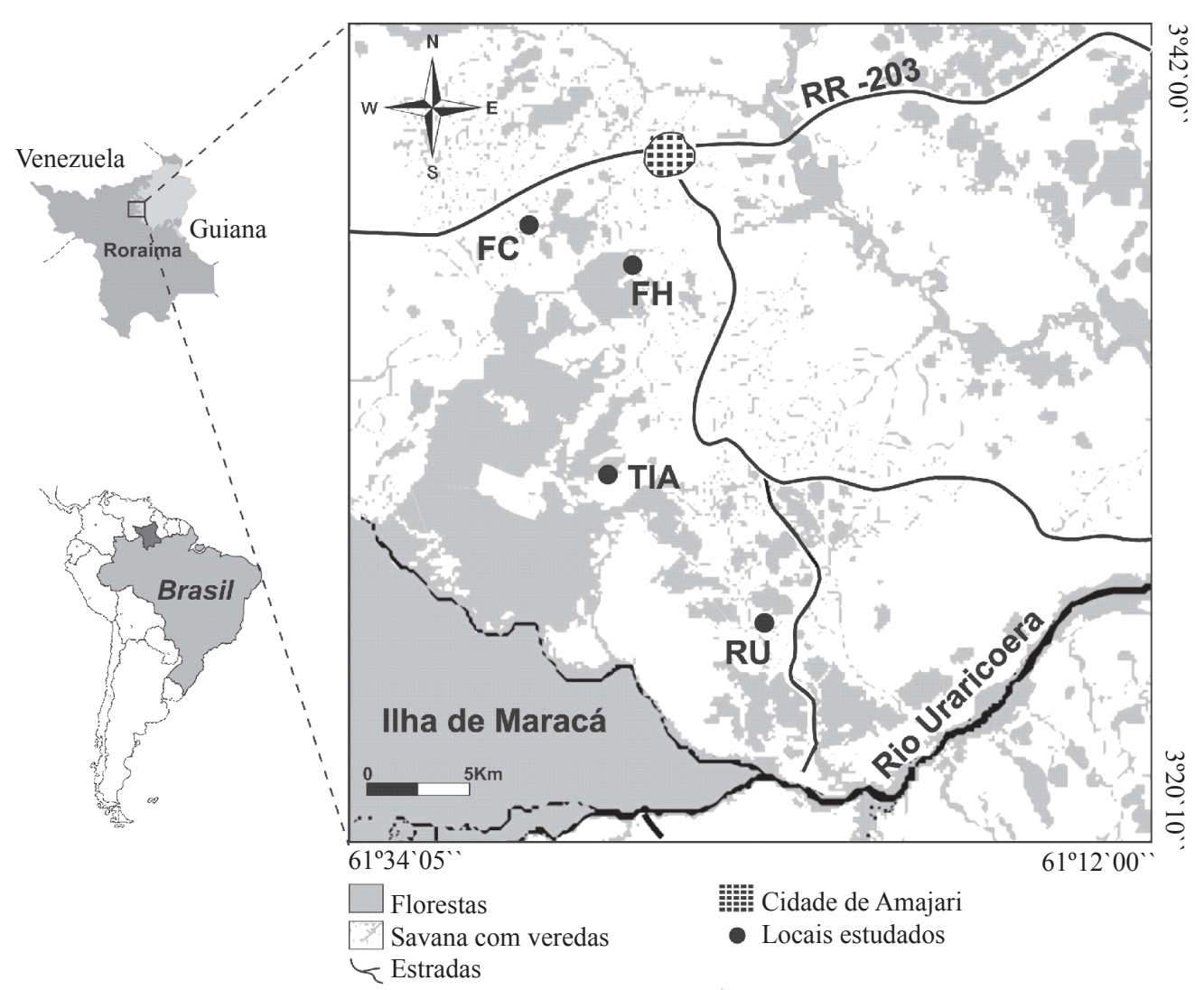

Figura 1 - Localização geográfica da área estudada inserida em uma área de transição savana-floresta e os locais de amostragem das topossequências - FC: Fazenda Cigana; FH: Fazenda Humaitá; TIA: junto a Terra Indigena Aningal e RU: Rio Uraricoera. 
O clima da área estudada é tropical úmido (Awi, conforme a classificação de Köppen), com temperatura média anual de $27^{\circ} \mathrm{C}$, e precipitação média anual de $1.500 \mathrm{~mm}$. Segundo Nimer (1991), o regime de precipitação define duas estações bem marcadas, uma seca (outubro a março) e outra chuvosa (abril a setembro), em oposição ao padrão dominante na Amazônia.

A área estudada compreende a zona de transição entre as savanas e a floresta classificada como estacional semidecidual (Sette Silva 1993). As savanas de um modo geral exibem estrato herbáceo dominado por gramíneas (Poaceae e Cyperaceae) permeadas por arbustos e/ou árvores retorcidas de folhas grossas, como a Curatella americana (Dilleniaceae) e Byrsonima crassifolia (Malpighiaceae), segundo Miranda \& Absy (1997). A estrutura e composição florística seguem, por vezes, as variações topográficas e consequentemente as variações do lençol freático. Dessa maneira, em áreas planas e rebaixadas sujeitas periodicamente a alagamentos (campos hidromórficos) predominam as savanas do tipo graminosa. Por outro lado, nas áreas mais elevadas que constituem os divisores da rede de drenagem, as savanas assumem fisionomia arbustiva ou mesmo arbórea, onde as principais espécies Curatella americana e Byrsonima crassifolia se aglomeram juntamente com outras espécies como a Xylopia aromatica (Annonaceae) e Bowdichia virgilioides (Fabaceae). Esta última, com ocorrência também em meio às áreas florestadas (Figs. 2A e B).

As veredas formadas pelo enfileiramento serpenteante de palmeiras de Mauritia flexuosa (Arecaceae), popularmente conhecidas como buritis, recortam frequentemente as savanas. Essas veredas ocupam as áreas deprimidas do terreno, onde o lençol freático aflora pelo menos durante a estação chuvosa, embora também ocorram extensivamente ao longo de estreitos cursos d'água (igarapés), desempenhando o papel de mata de galeria (Fig. 2C).
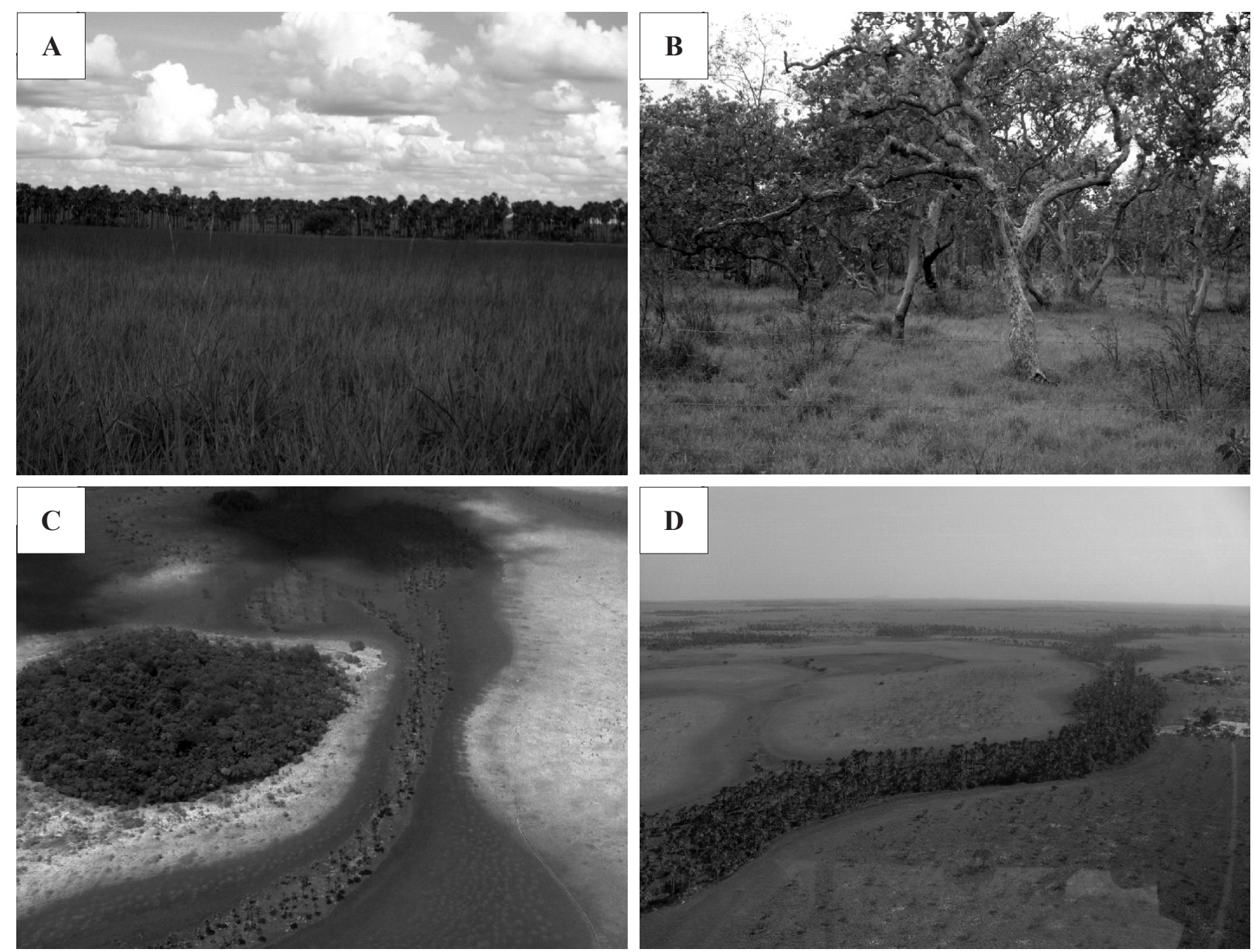

Figura 2 - Aspectos da cobertura vegetal da paisagem de transição savana-floresta. (A) savana graminosa com veredas de buritis ao fundo; (B) savana arbórea dominada por Curatella americana e Byrsonima crassifolia; (C) extensas veredas recortando as savanas; (D) ilhas circulares de floresta ocupando áreas mais elevadas do terreno, destaque também para vereda de buritis e brejos ocupando suaves depressões. 
As florestas, por sua vez, ocorrem em manchas e corredores em meio à savana. Quando em manchas, assumem geralmente a forma de ilhas circulares ou elipsoidais e ocupam o topo de morrotes (Fig. 2D), ou mesmo os vales e encostas do relevo de anfiteatros. Os corredores de floresta aparecem ao longo de rios e igarapés de maiores extensões e com maior volume hídrico constituindo as verdadeiras matas de galeria.

Os terrenos geológicos têm como substrato quartzitos, itabiritos, anfibolitos, quartzo-mica xistos e anfibólio xistos do Grupo Cauarane (Montalvão $\&$ Pitthan 1974), sobre os quais se formaram coberturas pedológicas representadas por latossolos amarelos e vermelho-amarelos, formações lateríticas imaturas e depósitos coluvionares compostos por materiais provenientes de todos esses materiais e detritos rochosos, aqui coletivamente denominados de regolitos. O relevo esculpido sobre esses solos e/ou as rochas do substrato variam de plano a suavemente ondulado, ou mesmo colinoso com altitudes entre 70 e $200 \mathrm{~m}$ acima do nível do mar.

\section{MATERIAIS E MÉTODOS}

Amostragem Visando investigar o arranjo dos regolitos (solos, lateritos e sedimentos) e entender suas relações e dos demais constituintes da paisagem (relevo, cobertura vegetal, corpos hídricos, etc.), foram selecionados quatro transectos ao longo de vertentes do relevo nas áreas da Fazenda Cigana (FC), Fazenda Humaitá (FH), nos arredores da Terra Indígena Aningal (TIA) e nas proximidades do rio Uraricoera (RU), denominados aqui de topossequências (ver Fig. 1). Nas depressões ocupadas por veredas de buritis, foram coletadas amostras de sedimentos com o auxílio de um trado manual tipo Russo. Ao longo das topossequências, as amostras foram coletadas com auxílio de trado convencional para solos, alcançando até $1 \mathrm{~m}$ de profundidade ou em trincheiras abertas para esse fim. A amostragem para cada topossequência (incluindo-se as veredas) está indicada na Fig. 3. As topossequências selecionadas representam os padrões geomórficos, pedológicos e botânicos encontrados na região aqui estudada.

Análises granulométricas As análises granulométricas consistiram na separação das frações areia, silte e argila, através de peneiramento em meio úmido conforme procedimentos da Embrapa (1997). Nos grãos da fração areia, avaliou-se o grau de arredondamento e esfericidade, por comparação visual com as tabelas de classes de arredondamento e esfericidade apresentadas por Suguio (2003).

Análises mineralógicas e químicas Os minerais constituintes foram determinados por difração de raios-X (DRX) em amostra total, método do pó. Para a caracterização dos argilominerais, empregou-se a fração argila, assentada em lâmina orientada, glicolada e aquecida.

As análises de DRX foram realizadas com auxílio de um difratômetro de raios-X de marca PANalytical, modelo X'PERT PRO MPD (PW 3040/60), com goniômetro PW 3050/60 (Teta/ Teeta), modelo PW3373/00, foco fino longo, 2200W, $60 \mathrm{Kv}$ e com tubo de raios-X cerâmico, anodo de Co

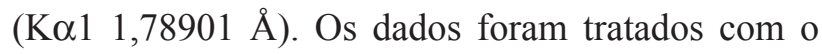
software X'Pert HighScore versão 2.1b, também da PANalytical.

As análises químicas para a quantificação dos elementos maiores e traços, incluindo os elementos terras raras (ETR), foram efetuadas a partir das amostras pulverizadas e fundidas com metaborato/tetraborato de lítio e solubilização ácida. Em seguida, os elementos químicos foram determinados por espectrometria de massas com fonte de plasma indutivamente acoplada (ICP-MS). Estas análises foram realizadas no ACMELABS Ltd.

\section{Datação radiocarbônica dos sedimentos}

Três amostras de sedimentos, cada uma representativa da porção basal dos testemunhos coletados em três diferentes veredas, foram datadas por radiocarbono com a técnica de acelerador de espectrometria de massa (AMS) no laboratório do Physikalisches Institut da Universidade de Erlangen, na Alemanha. As idades C-14 obtidas foram calibradas em anos antes do presente (AP) através do software CALIB 6.0 (Stuiver \& Reimer 1993).

\section{RESULTADOS E DISCUSSÃO}

As topossequências e os solos As topossequências Fazenda Cigana (FC) e Rio Uraricoera (RU) ocorrem em áreas de savanas predominantemente graminosas em relevo suave ondulado e/ou plano, onde as florestas se manifestam em ilhas de formato circular no topo de morrotes (RU) ou corredores de mata ciliar entrelaçada com as palmeiras de Mauritia flexuosa (FC) 
(Figs. 3A e D). As topossequências Fazenda Humaitá (FH) e Terra Indígena Aningal (TIA) situam-se em áreas de relevo colinoso escalonado em anfiteatros côncavo-convexos com vales de fundo chatos, onde o contato entre savanas e florestas é ligeiramente abrupto. Ilhas de florestas ocorrem nos vales em associação com as palmeiras de buritis (vereda), por vezes, fenecidas. O déficit hídrico ocasionado pelo assoreamento do canal (FH) e/ou a competição com as espécies da floresta emergente, a qual se alonga também em direção às encostas dos anfiteatros marginais podem ser as causas da rarefação das palmeiras e o consequente desaparecimento precoce do ambiente de veredas (Figs. 3B e C).

$\mathbf{A}$

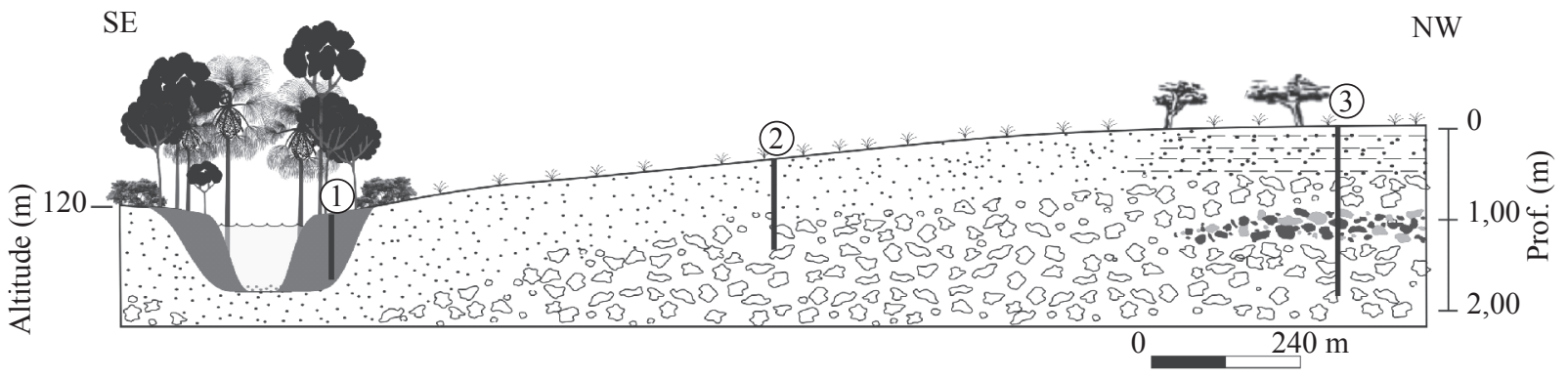

B

$\mathrm{NE}$

(5)

SW

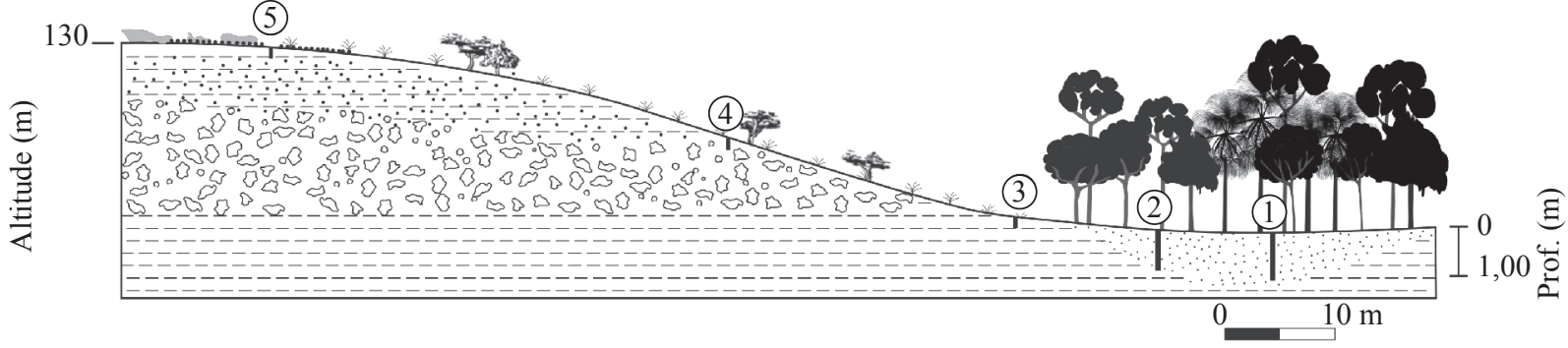

C

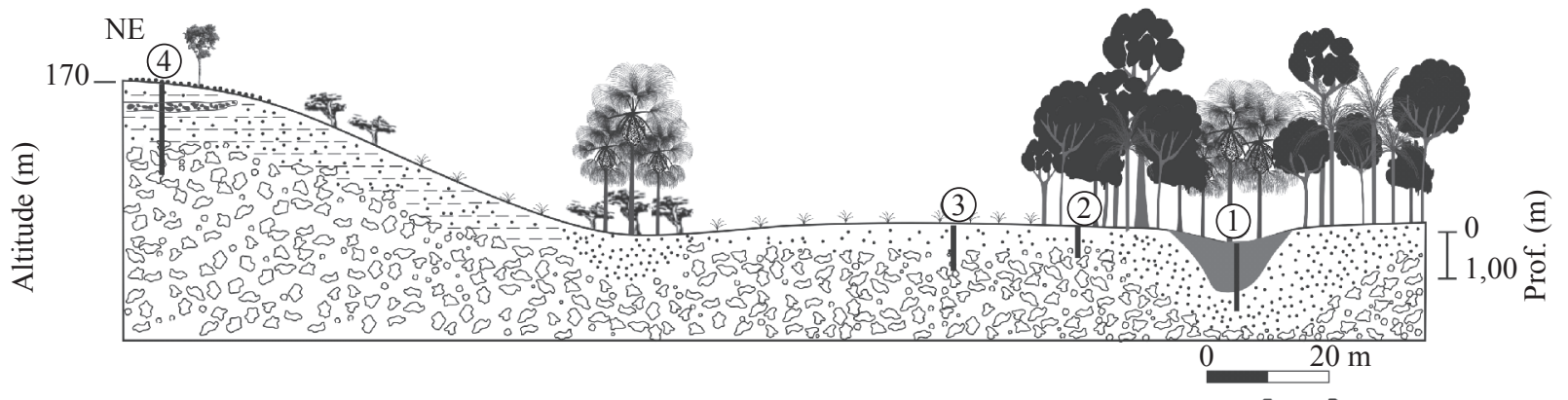

D

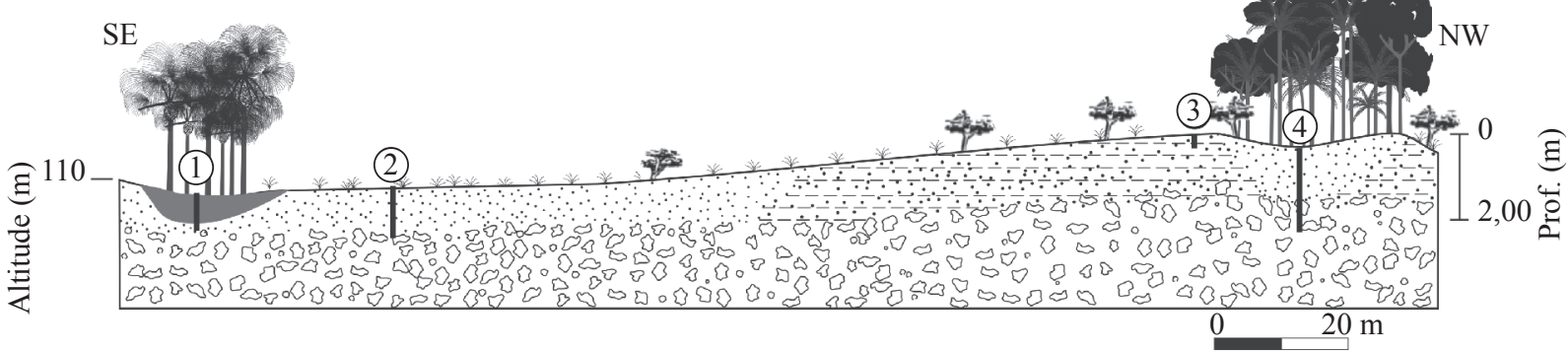

Regolitos

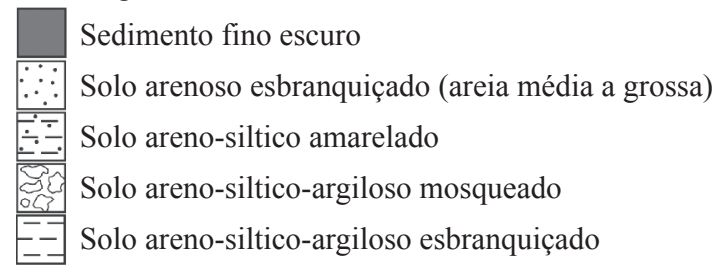

\begin{tabular}{l} 
Lag (esferolitos de quartzo e oxi-hidróxidos de Fe) \\
\hline Franmentos de quartzo ( $\sim 60 \mathrm{~cm}$ de diametro)
\end{tabular}
crostas lateríticas
cinha de pedra composta por fragmentos de quartzo e
Pontos de sondagem e amostragem $(1-5)$

Figura 3 -Esquemas longitudinais das topossequências, destacando os pontos de sondagem e amostragem e a distribuição da cobertura vegetal e pedológica ao longo das vertentes. (A) Fazenda Cigana (FC); (B) Fazenda Humaitá (FH); (C) Terra Indígena Aningal (TIA); (D) Rio Uraricoera (RU). 
As observações em campo mostram que as topossequências abrangem os seguintes materiais regolíticos: no horizonte subsuperficial destacam-se materiais areno-síltico-argilosos de aspecto mosqueado, que sobrepõem um horizonte areno-síltico esbranquiçado. Esses materiais correspondem à zona saprolítica de um perfil de alteração intempérica, em que a zona mosqueada se sobrepõe à pálida. $\mathrm{O}$ material mosqueado muda em direção à superfície para um solo areno-síltico amarelado na parte superior da encosta ou vertente e para arenoso cinza-esbranquiçado na zona inferior da mesma em todas as topossequências investigadas (Figs. 3A-D). Os dados granulométricos confirmam a textura arenosa dos regolitos, com pouca variação para aquelas de natureza areno-síltica (Tab. 1). A morfologia dos grãos de areia dos solos é dominada pelos angulosos (cerca de 70\%), seguidos dos subangulosos (20\%) e subarredondados. Isso sugere proximidade com a área fonte. Cerca de 90\% dos grãos apresenta baixa esfericidade, predominando formas achatadas e alongadas reforçando a ideia de pouco transporte.

Tabela 1 - Atributos granulométricos, texturais e de cor dos regolitos (saprólito pálido e mosqueado, solos e linhas de pedras) que constituem as topossequências

\begin{tabular}{|c|c|c|c|c|c|c|}
\hline \multirow{2}{*}{ Perfil } & \multirow{2}{*}{$\begin{array}{l}\text { Profundidade } \\
\quad(\mathrm{cm})\end{array}$} & \multicolumn{3}{|c|}{ Granulometria (\%) } & \multirow{2}{*}{ Textura $^{\text {(a) }}$} & \multirow{2}{*}{$\begin{array}{c}\text { Cor } \\
\text { (úmida) }\end{array}$} \\
\hline & & Areia & Silte & Argila & & \\
\hline \multicolumn{7}{|c|}{ TOPOSSEQUÊNCIA FAZENDA CIGANA (FC) } \\
\hline \multirow{5}{*}{ Perfil - 2} & $0-20$ & 84,53 & 13,37 & 2,1 & Areia & $10 Y R 6 / 2$ \\
\hline & $20-40$ & 84,63 & 13,8 & 1,57 & Areia & 10YR $7 / 1$ \\
\hline & $40-60$ & 85,06 & 12,68 & 2,26 & Areia & 10YR $7 / 1$ \\
\hline & $60-80$ & 85,51 & 11,99 & 2,5 & Areia & 10YR 7/1 \\
\hline & $80-100$ & 62,46 & 27,61 & 9,93 & Areia síltica & 10YR 8/1 \\
\hline \multirow{2}{*}{ Perfil - 3} & $0-40$ & 59,8 & 24,92 & 15,28 & Areia síltica & $5 \mathrm{YR} 5 / 6$ \\
\hline & $40-190$ & 35,18 & 34,18 & 30,64 & Areia síltico-argilosa & 5YR 5/6 \\
\hline \multicolumn{7}{|c|}{ TOPOSSEQUÊNCIA FAZENDA HUMAITÁ (FH) } \\
\hline \multirow{4}{*}{ Perfil - 2} & $0-20$ & 94,29 & 4,5 & 1,21 & Areia & $10 Y R 7 / 2$ \\
\hline & $20-40$ & 94,3 & 4,1 & 1,6 & Areia & $10 Y R 7 / 2$ \\
\hline & $40-60$ & 92,4 & 5,4 & 2,2 & Areia & 10YR 5/1 \\
\hline & $60-80$ & 91,15 & 6,01 & 2,84 & Areia & 10YR 5/1 \\
\hline Perfil - 3 & $0-20$ & 54,81 & 26,62 & 18,57 & Areia síltica & $10 Y R 7 / 2$ \\
\hline Perfil - 4 & $0-20$ & 64,85 & 27,13 & 8,02 & Areia síltica & 10YR 6/8 \\
\hline Perfil - 5 & $0-50$ & 68,23 & 24,77 & 7 & Areia síltica & $10 Y R 6 / 8$ \\
\hline \multicolumn{7}{|c|}{ TOPOSSEQUÊNCIA TERRA INDIGENA ANINGAL (TIA) } \\
\hline \multirow{4}{*}{ Perfil - 2} & $0-20$ & 83,38 & 12,52 & 4,1 & Areia & 10 YR $5 / 3$ \\
\hline & $20-40$ & 80,61 & 16,69 & 2,7 & Areia & 10YR 5/3 \\
\hline & $40-60$ & 75,69 & 18,23 & 6,08 & Areia & $10 Y R 5 / 3$ \\
\hline & $60-80$ & 74,18 & 23,08 & 2,74 & Areia & $10 Y R 5 / 3$ \\
\hline \multirow{5}{*}{ Perfil - 3} & $0-20$ & 94,97 & 3,95 & 1,08 & Areia & $10 Y R 7 / 2$ \\
\hline & $20-40$ & 93,69 & 5,4 & 0,91 & Areia & 10YR $7 / 2$ \\
\hline & $40-60$ & 93,13 & 6,59 & 0,28 & Areia & $10 Y R 7 / 2$ \\
\hline & $60-80$ & 93,66 & 5,09 & 1,25 & Areia & $10 Y R 7 / 2$ \\
\hline & $80-100$ & 91,78 & 6,3 & 1,92 & Areia & 10YR 8/1 \\
\hline \multirow{2}{*}{ Perfil - 4} & $0-100$ & 41,73 & 25,97 & 32,3 & Areia síltico-argilosa & 10 YR $6 / 8$ \\
\hline & $100-120$ & 35,51 & 33,65 & 30,84 & Areia síltico-argilosa & 7.5 YR 5/8 \\
\hline \multicolumn{7}{|c|}{ TOPOSSEQUÊNCIA RIO URARICOERA (RU) } \\
\hline \multirow{5}{*}{ Perfil - 2} & $0-20$ & 90,7 & 6,61 & 2,69 & Areia & $10 Y R 7 / 2$ \\
\hline & $20-40$ & 93,17 & 5,49 & 1,34 & Areia & $10 Y R 7 / 2$ \\
\hline & $40-60$ & 93,13 & 5,21 & 1,66 & Areia & 10YR $7 / 2$ \\
\hline & $60-80$ & 83,46 & 10,89 & 5,65 & Areia & 10YR $7 / 2$ \\
\hline & $80-100$ & 79,4 & 13,25 & 7,35 & Areia síltica & $10 Y R 7 / 2$ \\
\hline Perfil - 3 & $0-20$ & 41,86 & 33,89 & 24,25 & Areia síltica & 10YR 6/8 \\
\hline \multirow{3}{*}{ Perfil - 4} & $0-20$ & 81,91 & 14,33 & 3,76 & Areia & $10 \mathrm{YR} 5 / 3$ \\
\hline & $20-60$ & 78,13 & 15,62 & 6,25 & Areia & $10 Y R 5 / 3$ \\
\hline & $80-100$ & 43 & 25,63 & 31,37 & Areia síltico-argilosa & 10YR 6/8 \\
\hline
\end{tabular}

${ }^{\mathrm{a} C}$ Classificação conforme Shepard (1954). 
Linhas de pedras, formadas por fragmentos centimétricos de quartzo leitoso e em parte hialino, bem como de crostas ferruginosas são comuns na paisagem estudada. Estas costumam ser descontínuas e com espessura variável e inferior a $40 \mathrm{~cm}$, descrevem uma paleosuperfície ligeiramente ondulada, instalada entre a zona mosqueada e os solos amarelos do topo (Fig. 4A), o que pode indicar a natureza alóctone dos solos. Algumas destas linhas de pedras provêm da fragmentação de veios de quartzo in situ ou transportados por gravidade a partir de áreas mais elevadas circundantes.

Acúmulos superficiais representados por tapetes de concreções, esferolitos e fragmentos de oxi-hidróxidos de ferro (OHFe) e de quartzo representam depósitos coluviais do tipo lags (Figs. 3 e 4B). No topo das topossequências FH e TIA esses tapetes ou lags estão localmente soterrados pelo solo areno-síltico (Fig. 3), e, portanto, constituem linhas de pedras recentes. Os fragmentos e esferolitos de OHFe correspondem a relictos das crostas ferruginosas. Embora as crostas lateríticas sejam feições muito comuns na paisagem de savanas de Roraima, onde ocupam o topo de morrotes, na área investigada elas são de ocorrência restrita.

No fundo dos vales abertos e nos locais onde aflora o lençol freático, observou-se a instalação de áreas úmidas, que receberam por run off material síltico e argiloso das encostas de solos arenosos a areno-sílticos, por ocasião de enxurradas. Nesses locais onde as veredas se instalaram, formaram-se depósitos de sedimentos finos (silte e argila) escuros, ricos em matéria orgânica, que atingem até $1,5 \mathrm{~m}$ de espessura.

\section{Os sedimentos das veredas: aspectos litológicos e} cronológicos Os corpos de sedimentos das veredas variam muito quanto à espessura, textura e idade (Tab. 2). Os sedimentos arenosos da vereda de FH não puderam ser datados por falta de material
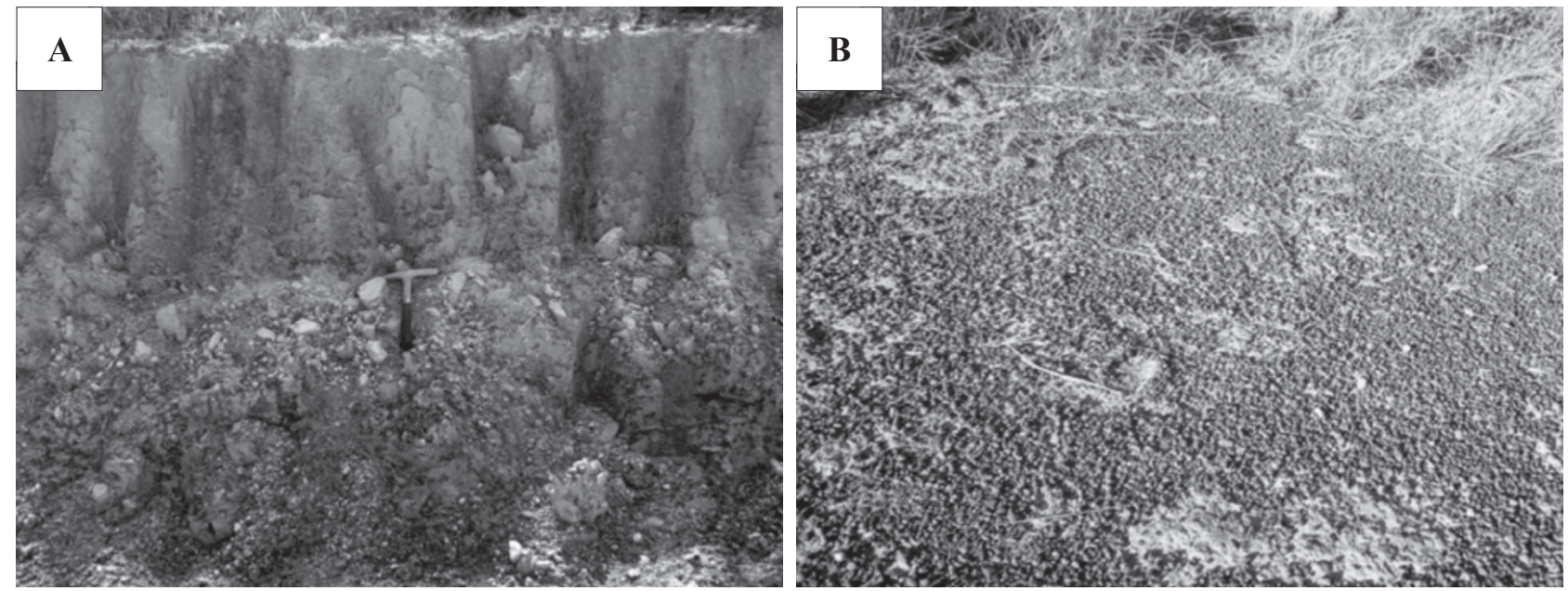

Figura 4 - Solo arenoso, tendo na base linha de pedra composta por fragmentos de quartzo e restritamente de crostas ferruginosas sobreposta ao saprólito mosqueado (A); tapete superficial formado pelo acúmulo de esferolitos de OHFe e fragmentos de quartzo, em consequência da lixiviação dos finos por run off, instalados sobre e, em parte, derivados dos solos areno-sílticos amarelados no topo alto das vertentes (B).

Tabela 2 - Descrição litológica e cronologia da base dos testemunhos de sedimentos das veredas situadas nos vales das topossequências estudadas

\begin{tabular}{|c|c|c|c|}
\hline $\begin{array}{l}\text { Vereda } \\
\text { (Perfil) }\end{array}$ & Profundidade $(\mathrm{cm})$ & Descrição litológica & $\begin{array}{l}\text { Início da vereda (anos calibrados } \\
\text { antes do presente -AP) }\end{array}$ \\
\hline \multirow{4}{*}{ FC-1 } & $0-27$ & Argila síltica, cinza escura contendo restos vegetais & \multirow{4}{*}{1550 anos } \\
\hline & $27-80$ & Silte arenoso cinza escuro com raízes & \\
\hline & $80-120$ & Silte arenoso marrom claro com bandas alaranjadas & \\
\hline & $120-150$ & Areia fina preta com restos vegetais & \\
\hline \multirow{4}{*}{ TIA-1 } & $0-30$ & Argila síltica preta rica em matéria orgânica decomposta & \multirow{4}{*}{1200 anos } \\
\hline & $30-55$ & Argila síltica cinza escura & \\
\hline & $55-75$ & Areia fina cinza escura & \\
\hline & $75-150$ & $\begin{array}{l}\text { Areia grossa compacta com fragmentos de quartzo }(3 \mathrm{~cm}) \\
\text { tons esverdeados com bandas alaranjadas }\end{array}$ & \\
\hline \multirow{2}{*}{ RU-1 } & $0-47$ & Silte argiloso cinza escuro com presença de macrorrestos vegetais & \multirow{2}{*}{ Atual } \\
\hline & $47-75$ & Areia incoesa castanho-amarronzada & \\
\hline
\end{tabular}


adequado para este fim, enquanto que aqueles provenientes da vereda de RU, com domínio de silte e ricos em matéria orgânica, apresentaram idade radiocarbono negativa, indicando formação moderna.

Na sequência da vereda TIA, que compreende material arenoso nos primeiros $75 \mathrm{~cm}$ basais e argila síltica rica em matéria orgânica nos $75 \mathrm{~cm}$ superiores, os resultados mostram que a sedimentação com acúmulo de matéria orgânica se iniciou há $1.346 \pm 40$ anos, calibrada em 1.200 anos AP, marcando o início das condições mais úmidas neste local. Na vereda da topossequência FC, os sedimentos finos com matéria orgânica começaram a se acumular a partir de $1.718 \pm 40$ anos, idade calibrada em 1.550 anos AP.

Esses dados evidenciam o caráter jovem das veredas, cuja presença resulta da farta disponibilidade hídrica nos solos que propicia a formação de brejos colonizados por vegetação herbácea e, em seguida, a instalação das palmeiras.

MINERALOGIA Os regolitos arenosos e areno-siltosos a argilosos estudados são compostos essencialmente por quartzo e caulinita, acessoriamente muscovita, microclínio e albita (Fig. 5A). Os dois últimos minerais indicam elevada imaturidade dos regolitos e/ou área fonte proximal. Nas topossequências RU e TIA, além desses minerais, ocorre também sillimanita (Fig. 5B), uma forte evidência da contribuição de rochas metamórficas. Hematita e
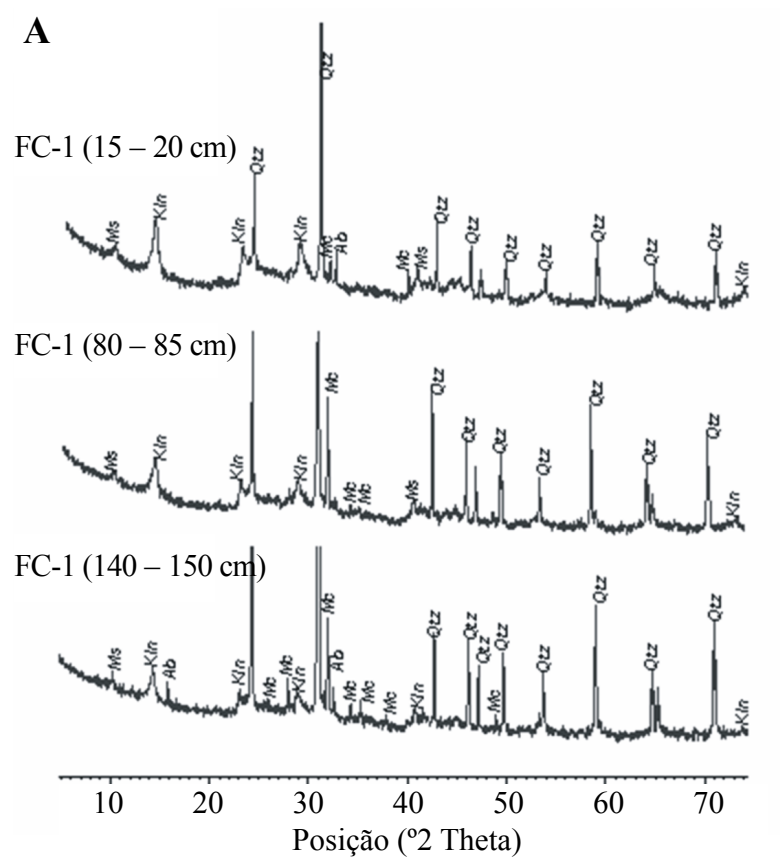

goethita estão presentes apenas nas zonas saprolíticas mosqueadas de todas as topossequências. $\mathrm{Na}$ fração $<2 \mathrm{~mm}$, a caulinita foi o único mineral de argila identificado, o que mostra o elevado índice de alteração intempérica desses regolitos. A presença concomitante de minerais estáveis e instáveis atesta a participação de rochas com diferentes graus de truncamento, do topo ao saprólito ou mesmo rocha-sã proximal, e relativa atividade erosional.

De uma forma geral, as assembleias mineralógicas identificadas nos regolitos mostram uma grande afinidade, entre sedimentos das veredas e o saprólito, e seu respectivo manto de solos, sugerindo que derivaram de uma mesma fonte, com domínio de aluminossilicatos, de metapelitos metamorfizados em alto grau (presença de sillimanita nas veredas RU-1 e TIA-1). A presença de albita e microclínio, tanto nos sedimentos das veredas, como nos solos arenosos das encostas baixas, reforça a proveniência metamórfica (gnaisses) e indica rocha fonte proximal, como já demonstrado. Esses dados se coadunam com os conhecimentos prévios da geologia da área, cujas unidades geológicas são constituídas por gnaisses, xistos, anfibolitos e quartzitos do Grupo Cauarane.

\section{Composição química}

ELEMENTOS MAIORES E MENORES Os solos das topossequências e os sedimentos das veredas

$\mathbf{B}$
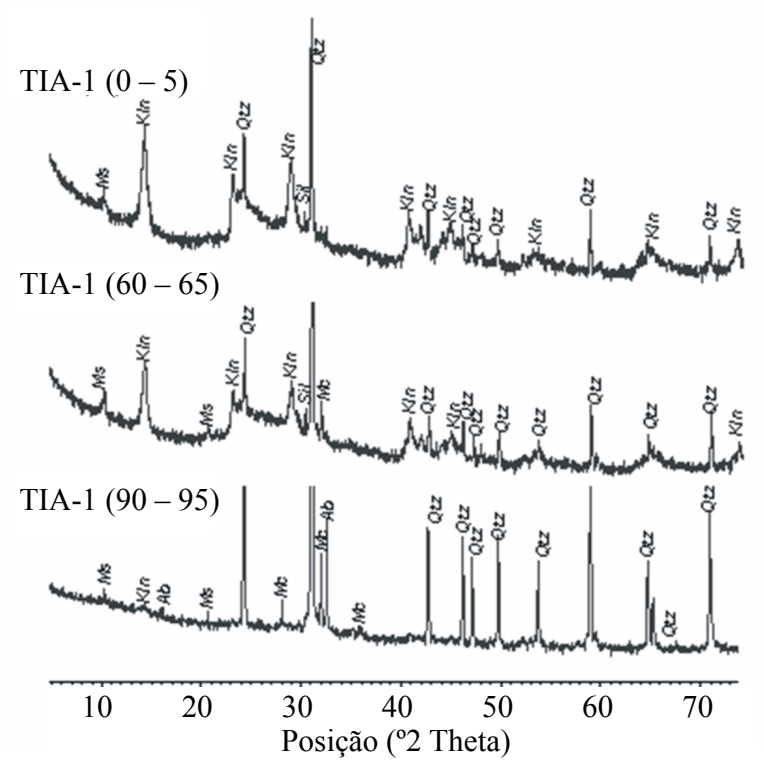

Figura 5 - Difratogramas de raios-x (CoK $\alpha$ ) mostrando as fases mineralógicas nos sedimentos das veredas (A) Fazenda Cigana (FC) e (B) Terra Indigena Aningal (TIA): quartzo (Qtz), caulinita (Kln), muscovita (Ms), microclínio (Mc), albita (Ab) e sillimanita (Sil). 
associadas são constituídos principalmente por $\mathrm{SiO}_{2}$ (46,14 a 98,56\%), e $\mathrm{Al}_{2} \mathrm{O}_{3}(0,75$ a $27,59 \%)$, em parte $\mathrm{Fe}_{2} \mathrm{O}_{3}(0,07$ a $14 \%), \mathrm{K}_{2} \mathrm{O}(0,03$ a $1,67 \%)$ e $\mathrm{TiO}_{2}(0,04$ a $1,1 \%$ ). Os teores de $\mathrm{MnO}, \mathrm{MgO}, \mathrm{CaO}, \mathrm{Na}_{2} \mathrm{O}, \mathrm{e}_{2} \mathrm{O}_{5}$ encontram-se abaixo de 0,04, 0,27 0,03 e 0,16\%, respectivamente. Os altos valores de $\mathrm{SiO}_{2}$ refletem a natureza quartzosa desses regolitos. Os valores mais altos de $\mathrm{Al}_{2} \mathrm{O}_{3}$ e $\mathrm{Fe}_{2} \mathrm{O}_{3}$ estão no saprólito mosqueado, respectivamente representando caulinita + muscovita e hematita + goethita. Os valores de $\mathrm{K}_{2} \mathrm{O}(0,03$ a $1,67 \%)$ estão associados a muscovita. Os valores médios (Fig. 6) deixam claro que os solos das altas encostas são mais ricos em $\mathrm{SiO}_{2}$, porém, mais pobres em $\mathrm{Al}_{2} \mathrm{O}_{3}, \mathrm{~K}_{2} \mathrm{O}$ e PF (representada por matéria orgânica - MO, principalmente). Essa composição química reflete o domínio de quartzo, com caulinita, sillimanita e muscovita, além da matéria orgânica, sendo que o quartzo predomina nos solos, enquanto caulinita, muscovita, sillimanita e MO, nos sedimentos das veredas.

Quando normalizadas às argilas australianas pós-arqueanas (PAAS) e mesmo aos valores crustais (Fig. 7), constata-se que são materiais empobrecidos em $\mathrm{Mn}, \mathrm{Mg}, \mathrm{Ca}, \mathrm{Na}$ e K, com maior destaque para $\mathrm{Ca}$, seguido por $\mathrm{Mg}$ e $\mathrm{Na}$, portanto, muito lixiviados, retratando as condições de intensa alteração intempérica, que tem reinado na região. Os solos são os materiais mais empobrecidos nesses elementos, enquanto que o saprólito mosqueado e os sedimentos se equivalem.

A comparação entre vários índices de alteração química, calculados para esses regolitos e para alguns padrões de referência, tais como os da crosta continental superior (CTS), PAAS, e granito, confirma o alto grau de intemperização sofrido por esses materiais, em relação a esses mesmos padrões. Porém, com valores dos índices CIA (índice químico de alteração) e CIW (índice químico de intemperismo) próximos ou iguais a 100, são similares aos solos e sedimentos de regiões próximas, como a Formação Boa Vista (FBV), planície do Rio Branco e crostas lateríticas (Fig. 8). O índice STI (índice sílica-titânio), desenvolvido especialmente para medir o grau de intemperismo de rochas metamórficas, apresenta valor médio de 83, corroborando a alteração química dos regolitos estudados. Os diagramas ternários da Fig. 9 permitem confirmar a dedução geológica suportada pela granulometria e mineralogia, em que os regolitos intempéricos (solos e saprólito mosqueado) foram a principal fonte dos sedimentos das veredas, carreados (lixiviação) por run off. As argilas, muito finas, foram carreadas para as depressões das veredas, enquanto o quartzo, mais grosso, acumulou-se relativamente nas vertentes, enquanto MO representa o acúmulo de detritos vegetais desenvolvidos na vereda, humificados.

A grande variação na composição química nos solos em si reflete a íntima ligação com seus distintos horizontes que estão bem delineados. Da mesma

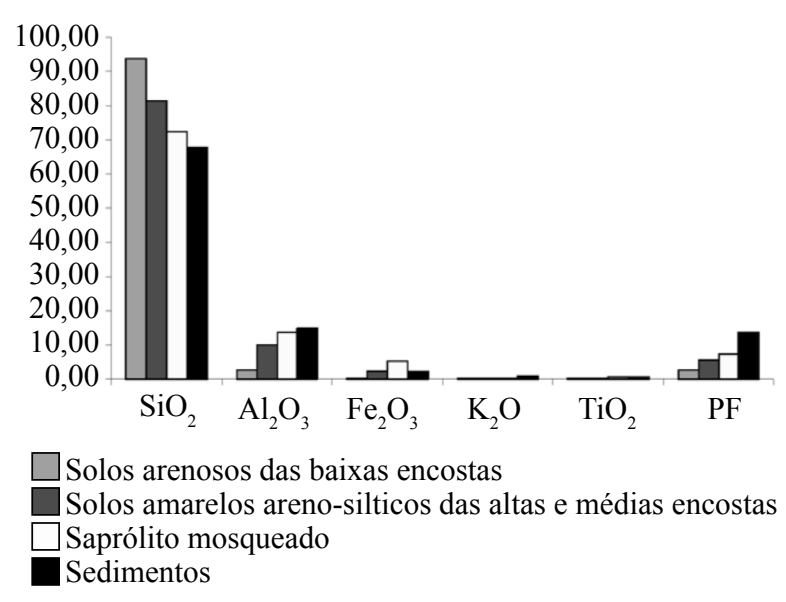

Figura 6 - Distribuição dos teores médios dos elementos maiores e perda ao fogo (PF) nos diferentes regolitos das topossequências.

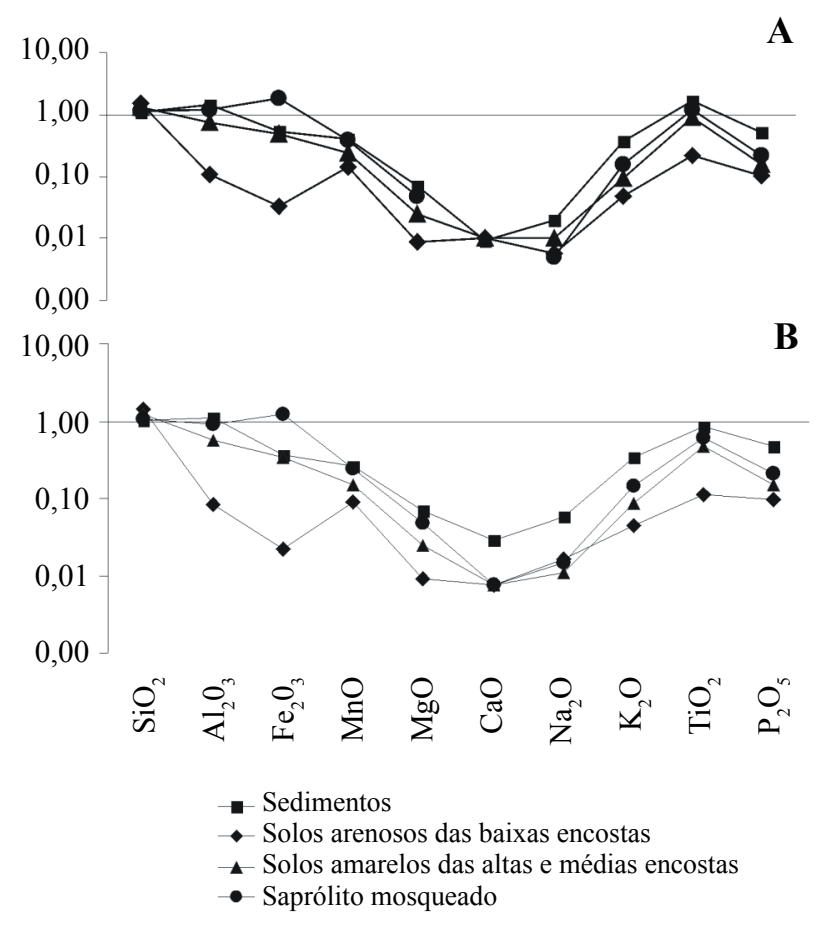

Figura 7 - Normalização dos valores médios dos elementos maiores nos regolitos em relação à crosta continental superior - CTS (A), a partir dos dados de Wedepohl (1995) e em relação ao padrão das argilas australianas pós-arqueanas - PAAS (B), segundo dados de Taylor \& McLennan (1985). 


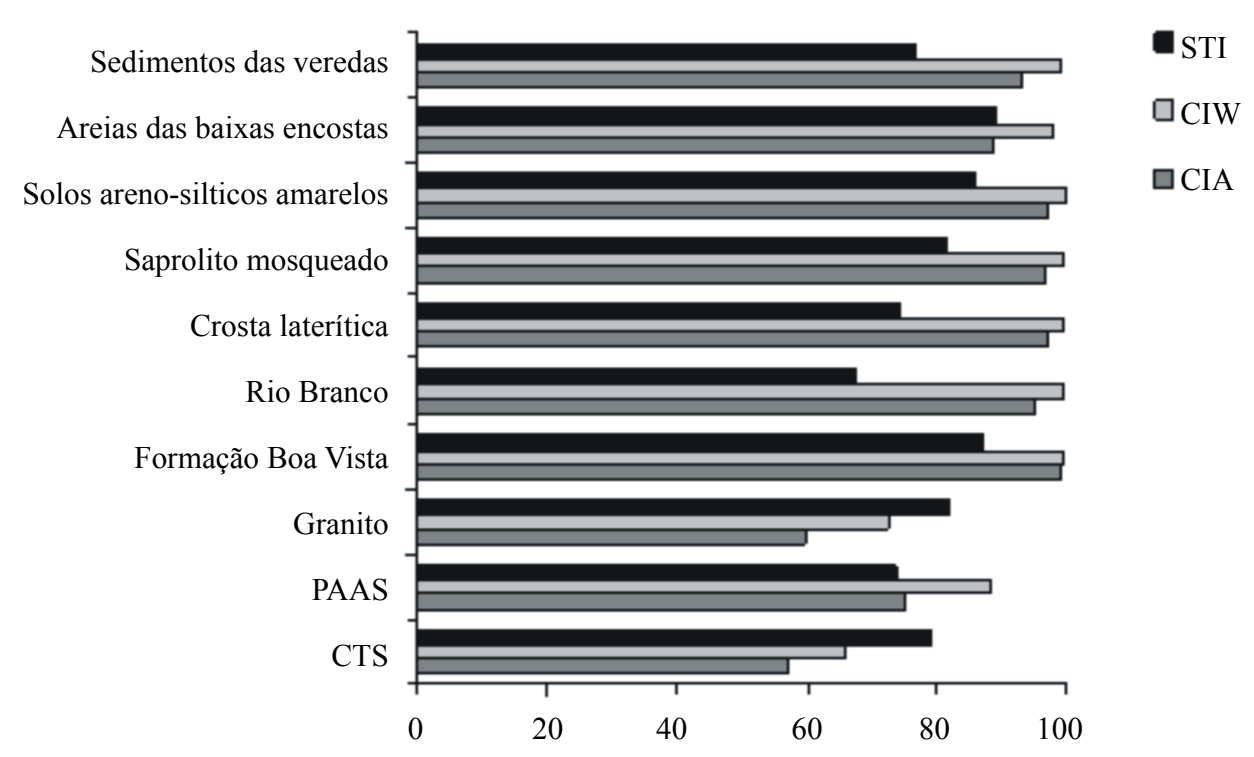

Figura 8 - Diferentes índices de alteração química para os materiais regolíticos da área de transição savanafloresta de Roraima, comparados entre si e aos padrões da crosta continental superior - CTS (Wedepohl 1995); das argilas australianas pós-arqueanas - PAAS (Taylor \& McLennan 1985); Rio Branco e Formação Boa Vista (Meneses et al. 2007). Índices de intemperismo - CIA: Índice Químico de Alteração; CIW: Índice Químico de Intemperismo; STI: Índice Sílica - Titânio. (Fonte: Price \& Velbel 2003).

forma, a grande variação nos sedimentos retrata a estruturação em domínio de areia na base dos perfis e de silte e argila, com matéria orgânica, no topo. A estratigrafia química observada nos sedimentos das veredas é espelhada pela diminuição nos valores de $\mathrm{SiO}_{2}$ e aumento de $\mathrm{Al}_{2} \mathrm{O}_{3}$ e $\mathrm{PF}(\mathrm{MO})$ em direção ao topo (Fig. 10). Os baixos teores de $\mathrm{Fe}_{2} \mathrm{O}_{3}, \mathrm{TiO}_{2}$ e $\mathrm{MgO}$ explicados pela lixiviação $\left(\mathrm{Fe}_{2} \mathrm{O}_{3}\right.$ e $\left.\mathrm{MgO}\right)$ e diluição pela $\mathrm{MO}\left(\mathrm{TiO}_{2}\right)$ mostram pouca variação ao longo dos perfis. Os OHFe em presença de MO humificada são decompostos, com $\mathrm{Fe}^{+3}$ reduzido e então lixiviados, podendo acumular-se no horizonte $\mathrm{B}$ espódico (hardpan) do podzol. $\mathrm{TiO}_{2}$ na forma de anatásio é estável, mas pode ser diluído pelo grande acúmulo de $\mathrm{MO}$, da mesma forma $\mathrm{SiO}_{2}$ como quartzo, que pode ser parcialmente solubilizado e sequestrado pelas formações graminosas e arbustivas.

\section{ELEMENTOS TRAÇOS E TERRAS RARAS}

Os regolitos da zona de transição savana-floresta em Roraima mostram concentrações dos elementos-traço em nível inferior aos valores da crosta superior, ou seja, são relativamente lixiviados, exceto para aqueles que classicamente se encontram em estruturas de minerais muito estáveis ao intemperismo, como zircão e anatásio, que estão relativamente enriquecidos. Destacam-se Sc, U, Th, Sc, Hf, Zr e Y, típicos de zircão, encontrado como acessório menor nos regolitos. $\mathrm{O}$ elemento $\mathrm{Ga}$ enriquece-se apenas nos materiais ricos em caulinita (saprólito e sedimentos). Por sinal, os sedimentos das veredas e o saprólito mosqueado se equivalem razoavelmente em termos de concentrações dos elementos-traço, enquanto se distanciam dos solos, que são, portanto, os materiais mais lixiviados, exceto para $\mathrm{U}, \mathrm{Zr}$ e Hf, também como zircão. Os solos, com a perda de minerais de argila e dos OHFe por eluviação e run off, enriquecendo-se cada vez mais em quartzo, consequentemente empobrecem nos elementos-traço relacionados com as argilas e goethita-hematita os quais vão, por sua vez, concentrar-se relativamente nos sedimentos das veredas. Elementos móveis $\mathrm{Ba}, \mathrm{Be}, \mathrm{Co}, \mathrm{Cu} \mathrm{Zn}, \mathrm{Cs}, \mathrm{Rb}$, $\mathrm{Sr}$, embora lixiviados, concentraram-se em relação aos solos (Fig. 11).

Os sedimentos e o saprólito mosqueado também se assemelham entre si em termos de concentrações dos elementos terras raras, principalmente em relação aos elementos terras raras pesados (ETRP), cujos valores estão ligeiramente enriquecidos quando confrontados com aqueles da crosta (CTS) (Fig. 12). Os solos encontram-se muito mais lixiviados em ETR, quando comparados com a CTS, mas com menor tendência para os ETRP, da mesma forma que os sedimentos e saprólito. O padrão de distribuição normalizado aos condritos é semelhante para todos os regolitos, com clara anomalia negativa de európio, mesmo de hólmio, e enriquecimento em elementos terras raras leves (ETRL) (Fig. 12), refletindo de 

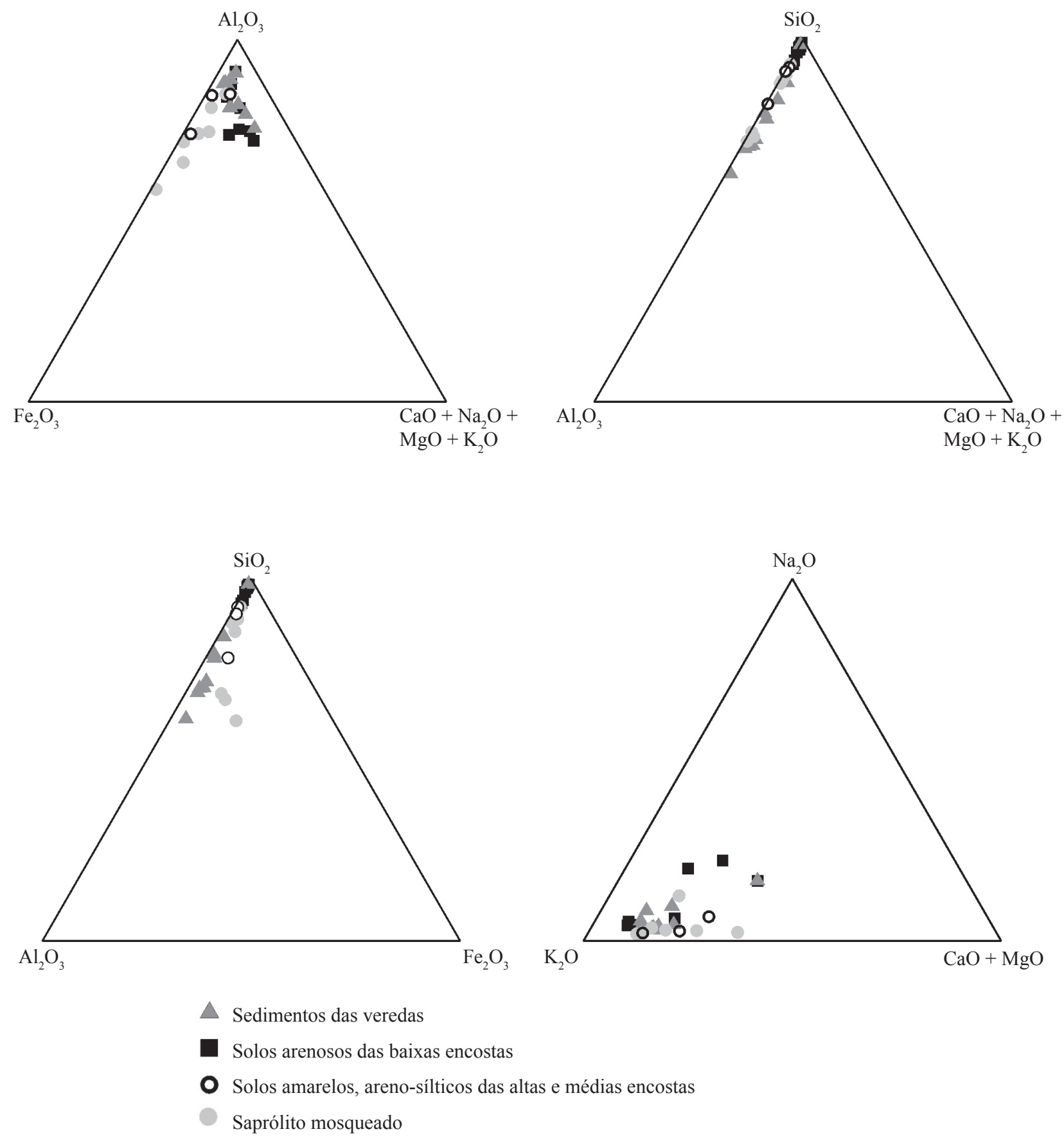

Figura 9 - Diagramas ternários comparando entre si a composição química dos diferentes regolitos, evidenciando o enriquecimento em $\mathrm{SiO}_{2}, \mathrm{Al}_{2} \mathrm{O}_{3}, \mathrm{Fe}_{2} \mathrm{O}_{3}$ e $\mathrm{K}_{2} \mathrm{O}$ e empobrecimento em álcalis (CaO, $\mathrm{MgO}, \mathrm{Na}{ }_{2} \mathrm{O}$ ).

certa forma o padrão desses elementos no mineral zircão, confirmando este mineral como hospedeiro desses elementos. A similaridade de comportamento dos ETR entre os diferentes regolitos mostra a afinidade mineralógica e química entre eles, e, portanto, laços de evolução.

CONSIDERAÇÕES FINAIS Os dados granulométricos, mineralógicos e geoquímicos demonstram que os regolitos aqui estudados são diferentes entre si, porém guardam forte afinidade entre si. São regolitos resultantes de intensa alteração intempérica, confirmados pelos diversos índices empregados para esse fim. Esses solos areno-quartzosos, ricos em $\mathrm{SiO}_{2}$ e extremamente pobres em álcalis servem indistintamente de substrato para ambas as formações vegetacionais, savana e floresta, e, portanto, não se constituem em barreiras à ocupação florestal. O lençol freático aflorante na base das vertentes promoveu o estabelecimento das veredas de buritis, e o consequente desenvolvimento da floresta ciliar associada à Mauritia flexuosa. 

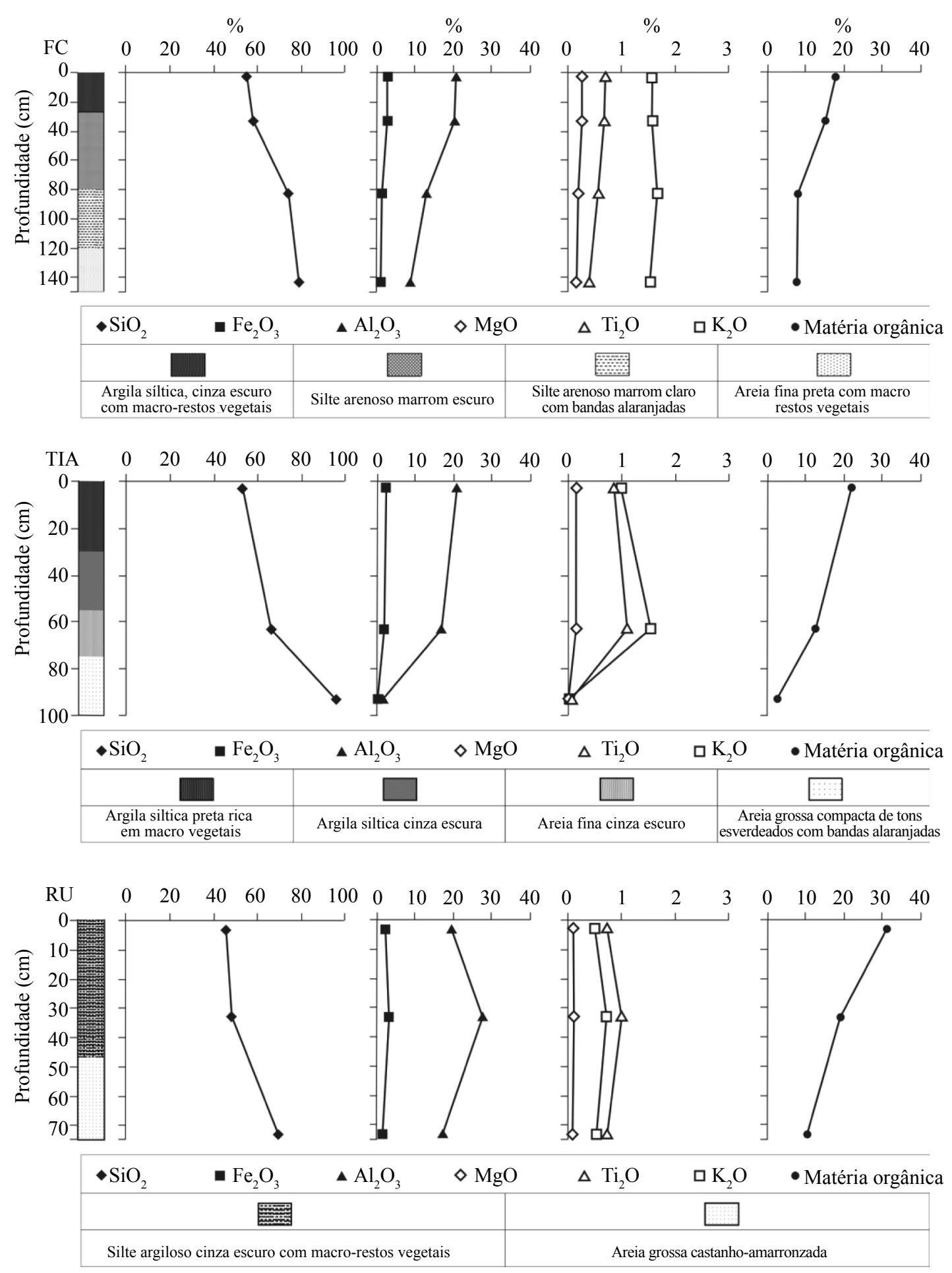

Figura 10 - Distribuição das concentrações de $\mathrm{SiO}_{2}, \mathrm{Fe}_{2} \mathrm{O}_{3}, \mathrm{Al}_{2} \mathrm{O}_{3}, \mathrm{MgO}$, $\mathrm{TiO}_{2}, \mathrm{~K}_{2} \mathrm{O}$ e matéria orgânica (MO) ao longo dos perfis de sedimentos das veredas. FC: Fazenda Cigana; TIA: Terra Indigena Aningal; RU: Rio Uraricoera.

Os segmentos de topo das topossequências $\mathrm{FH}$ e TIA (perfis FH-5 e TIA-4, respectivamente) exibem resquícios (esferolitos de oxi-hidróxidos de ferro compondo um lag na superfície ou em camadas soterradas pelo solo) do que foi uma crosta de perfil laterítico ferruginoso, à semelhança de muitas outras que ainda se mantêm preservadas nos domínios de savanas mais secas. Essas crostas retratam alternâncias de climas secos e úmidos atuantes na área durante o Pleistoceno e que, com o retorno de maior umidade, entram em desequilíbrio com o meio e sofrem degradação biofísica e bioquímica, o que resulta na geração de latossolos concrecionários (Tardy 1993). A transformação de crostas lateríticas em latossolos tem sido amplamente discutida no âmbito amazônico, e a atividade vegetal é apontada como um dos 


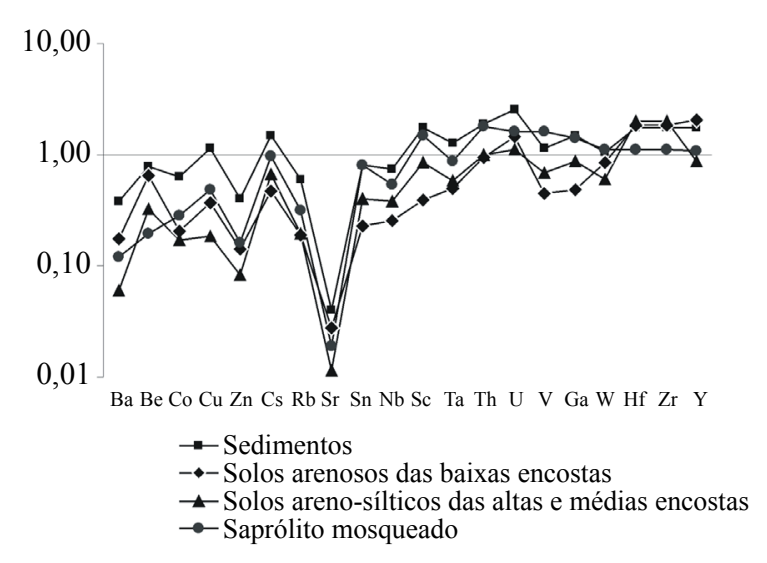

Figura 11 - Normalização dos valores médios de concentração dos elementos traços em relação à crosta terrestre (dados de Wedepohl 1995).

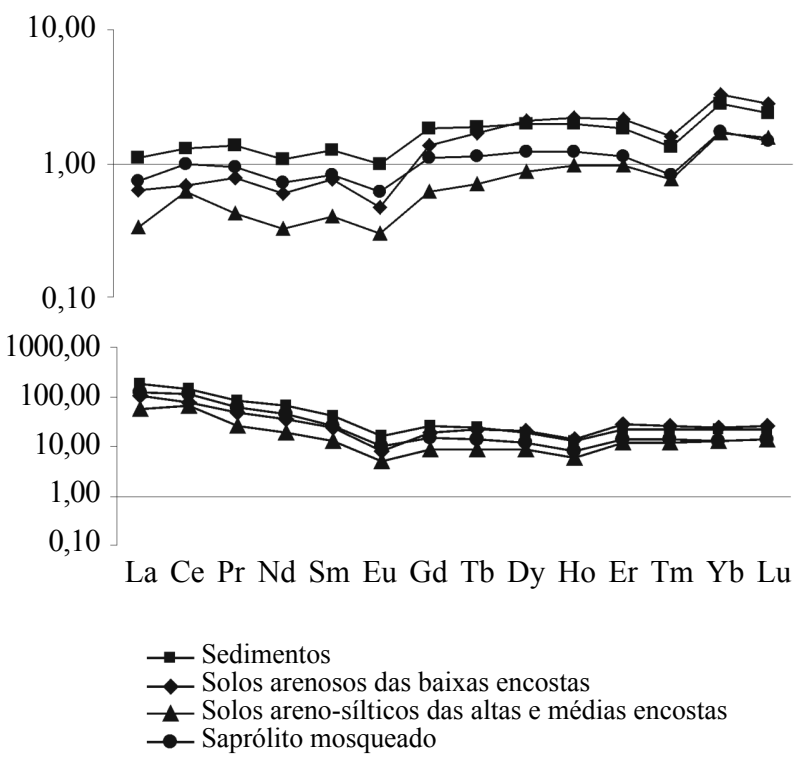

Figura 12 - Normalização dos valores médios de concentração dos elementos terras raras em relação à crosta terrestre segundo dados referenciais de Wedepohl (1995), e abaixo em relação aos condritos (dados de Evensen et al. 1978).

fatores importantes nesse processo (Horbe \& Costa 1997, 1999, 2005).

Os perfis lateríticos truncados ao nível do horizonte mosqueado contribuíram substancialmente com a formação in situ dos solos arenosos a areno-sílticos e, em conjunto, com a formação dos sedimentos das veredas As assinaturas mineralógicas e geoquímicas desses regolitos demonstram afinidades evolutivas entre eles.

A presença de linhas de pedras formadas por fragmentos provenientes de crostas lateríticas e de veios de quartzo denotam proximidade das áreas fontes e contribuição tanto de crostas como de saprólitos derivados dos metamorfitos. Evidenciam que a paisagem holocênica tardia sucedeu à outra, de domínio laterítico imaturo mais antigo, cuja formação relaciona-se a ciclos erosivos, impulsionados por condições semiáridas, que causaram a destruição das crostas lateríticas estabelecidas sobre rochas, como xistos, gnaisses e quartzitos com veios de quartzo, parcialmente intemperizadas. Dessa forma, promoveram o rebaixamento progressivo da topografia, com o esculpimento de morros sustentados por crostas e veios mais resistentes à erosão, e a formação de vales abertos sob savanas.

No Holoceno tardio, esses vales tornaram-se gradualmente úmidos, o que propiciou a instalação das veredas sobre os solos arenosos, contribuindo para que gradualmente se acumulassem detritos inorgânicos finos provindos por run off das encostas desprovidas de floresta e de detritos orgânicos.

Nessa conjuntura climática que perdura até os dias atuais, a farta disponibilidade hídrica nos solos favorece o estabelecimento e rápido desenvolvimento das veredas de Mauritia flexuosa ao longo da savana. Essas veredas são relativamente jovens se comparadas, por exemplo, àquelas do cerrado do Brasil Central datadas em até 7.000 anos AP (SalgadoLabouriau et al. 1997, Ferraz-Vicentini \& SalgadoLabouriau 1996), e a outras nos Llanos Orientales na Colômbia, cuja expansão se deu a partir de 4.000 anos AP, em decorrência de clima mais úmido e atividades antrópicas (Behling \& Hooghiemstra 2000).

As veredas mais antigas registradas neste trabalho encontram-se envolvidas por floresta (TIA e FC), indicando que estas são ambientes transitórios em meio a essa paisagem de florestas emergentes, ou seja, quando em contato com a floresta, essas veredas tendem a ser suprimidas devido a competição com os elementos arbóreos com quem passam a compartilhar o seu habitat. Em consequência, formam-se na paisagem extensos corredores de florestas (inicialmente ciliares) em substituição às veredas. Uma vez instalados, esses caminhos florestais vão se tornando cada vez mais largos à medida que se prolongam lateralmente a partir dos vales de veredas em direção às encostas do relevo colinoso, albergando áreas cada vez maiores e originando grandes retalhos de floresta em meio à savana remanescente.

Por outro lado, em áreas de relevo plano ou ligeiramente ondulado (RU e FC), nota-se um desenvolvimento de extensas faixas arenosas repletas 
de suaves depressões onde se instalam brejos sazonais com vegetação graminosa e adaptada a condições de hidromorfismo. O caráter areno-quartzoso evidenciado pelos altos teores de $\mathrm{SiO}_{2}$ das areias assemelha-se aqueles averiguados nas extensas planícies arenosas da região lacustre do entorno de Boa Vista onde se sugeriu a ocorrência de um processo de podzolização (Meneses et al. 2007). São também ambientes comparáveis em quase todas as suas características às areias encontradas nos espodossolos de outros locais da região amazônica (Dubroeucq \& Volkoff 1998, Horbe et al. 2004). Estes autores demonstram com clareza a formação de podzols a partir de latossolos.
$\mathrm{Na}$ área estudada, as condições de hidromorfismo, oscilação do lençol freático e escoamento superficial são os principais agentes responsáveis pela lixiviação dos argilominerais e óxi-hidróxidos de ferro do horizonte superficial. A ocorrência desses campos hidromórficos provavelmente pode constituir-se em um fator limitante ao avanço de floresta verificado nas áreas dominadas pelo relevo de anfiteatros.

AGRADECIMENTOS Os autores agradecem ao Conselho Nacional de Desenvolvimento Científico e Tecnológico $(\mathrm{CNPq})$ pelo apoio financeiro através da bolsa de doutorado concedida à primeira autora e de produtividade de pesquisa ao segundo autor.

\section{Referências}

Absy M.L., Cleef A.L.M., Fournier M., Martin L., Servant M., Sifeddine A., da Silva M.F., Soubiès F., Suguio K., Turcq B., Van der Hammen T. 1991. Mise en évidence de quatre phase d'ouverture de la forêt dense dans le sud-est de l'Amazonie au cours des 60 000 dernières années. Premiére comparaison avec d'autres régions tropicales. C.R. Académie Science Paris, 312(2):673-678.

Absy M.L., Prance G.T., Servant M.E., Miranda I.S. 1997. Registros Palinológicos em sedimentos do Holoceno e vegetação atual em Roraima. In: Barbosa R.I., Ferreira E.J.G., Castellón E.G. (eds). Homem, Ambiente e Ecologia no Estado de Roraima, Manaus, INPA, p. 463-480.

Behling H. \& Hooghiemstra H. 1998. Late Quaternary palaeoecology and palaeoclimatology from pollen records of the savannas of the Llanos Orientales in Colombia. Palaeogeography, Palaeoclimatology, Palaeoecology, 139(3):251-267.

Behling H. \& Hooghiemstra H. 2000. Holocene Amazon rain forest - savanna dynamics and climatic implications: High resolution pollen record Laguna Loma Linda in eastern Colombia. Journal of Quaternary Sciences, 15(7):687-695.

Bush M.B., De Oliveira P.E., Colinvaux P.A., Miller M.C., Moreno J.E. 2004. Amazonian paleoecological histories: one hill, three watersheds. Palaeogeography, Palaeoclimatology, Palaeoecology, 214(4):359-393.

Carneiro Filho A. 1991. Contribution to the study of the Forest-Savanna mosaic in the area of Roraima, northern Amazon basin, Brazil. Geopedologic. approach. Dissertação de Mestrado, University of Enschede, The Netherlands, 116 p.

Colinvaux P.A., De Oliveira P.E., Moreno J.E., Miller M.C., Bush, M.B. 1996. Along pollen record from lowland Amazonia: forest and cooling in glacial times. Science 247(5284):85-88.
Desjardins T., Carneiro Filho A., Mariotti A., Chauvel A., Girardin C. 1996. Changes of the forest-savanna boundary in Brazilian Amazonia during the Holocene revealed by stable isotope ratios of soil organic carbon. Oecologia, 108(4):749-756.

Dubroeucq D. \& Volkoff B. 1998. From Oxisols to Spodosols and Histosols: evolution of the soil mantles in the Rio Negro basin (Amazônia). Catena, 32(3):245-280.

Embrapa (Empresa Brasileira de Pesquisa Agropecuária). 1997. Manual de métodos de análise de solos. 2.ed., Rio de Janeiro, Embrapa, 212 p.

Evensen N.M., Hamilton P.J., O’nions R.K. 1978. Rareearth abundance in chondritic meteoritos. Geochimica et Cosmochimica Acta, 42(8):1199-1212.

Ferraz-Vicentini K.R., Salgado-Labouriau M.L. 1996. Palynological analysis of a palm swamp in central Brazil. Journal of South American Earth Science, 9(3):207-219.

Horbe A.M.C. \& Costa M.L. 1997. Solos gerados a partir do intemperismo de crostas lateríticas silicoferruginosas. Acta Amazonica, 27(4):241-256.

Horbe A.M.C. \& Costa M.L. 1999. Relações genéticas entre latossolos e crostas lateríticas aluminosas e aluminoferruginosas na região de Paragominas - Pará. Revista Brasileira de Geociências, 29(4):477-504.

Horbe A.M.C. \& Costa M.L. 2005. Lateritic crusts and related soils in eastern Brazilian Amazonia. Geoderma, 126(3):225-239.

Horbe A.M.C., Horbe M.A., Suguio K. 2004. Tropical Spodosols in northeastern Amazonas State, Brasil. Geoderma, 119(1):55-68.

Mayle F.E., Langstroth R.P., Fisher R.A., Meir P. 2007. Long-term forest-savannah dynamics in the Bolivian Amazon: implications for conservation. Philosophical Transactions of the Royal Society, 362(1478):291-308. 
Meneses M.E.N.S., Costa M.L., Costa J.A.V. 2007. Os lagos do lavrado de Boa Vista - Roraima: fisiografia, físico-química das águas, mineralogia e química dos sedimentos. Revista Brasileira de Geociências, 37(3):478-489.

Miranda I.S. \& Absy M.L. 1997. A flora fanerogâmica das savanas de Roraima. In: Barbosa R.I., Ferreira E.J.G., Castellón E.G. (Eds). Homem, Ambiente e Ecologia no Estado de Roraima, Manaus, INPA, p. 445-462.

Montalvão R.M.G. \& Pitthan J.H.L. 1974. Grupo Cauarane. In: Projeto RADAMBRASIL, Relatório interno 21-G, Belém, 7 p.

Nimer E. 1991. Clima. In: Geografia do Brasil: Região Norte, Rio de Janeiro, IBGE, p. 61-71.

Price J.R. \& Velbel M.A. 2003. Chemical weathering indices applied to weathering profiles developed on heterogeneous felsic metamorphic parent rocks. Chemical Geology, 202(3):397-416.

Salgado-Labouriau M.L., Casseti V., Ferraz-Vicentini K.R., Martin L., Soubiés F., Suguio K., Turq B. 1997. Late Quaternary vegetational and climatic changes in cerrado and palm swamp from Central Brazil. Palaeogeography, Palaeoclimatology, Palaeoecology, 128(1):215-226.

Sarmiento G. \& Monasterio M. 1975. A critical consideration of the environmental conditions associated with the occurrence of savanna ecosystems in tropical America. In: Golley F.B. \& Medina E. (eds). Tropical Ecological Systems, trends in terrestrial and aquatic research, Berlin, Springer-Verlag, p. 223-250.

Schaefer C.E.R. \& Dalrymple J. 1996. Pedogenesis and relict properties of soils with columnar structure from Roraima, north Amazonia. Geoderma, 71(1):1-17.
Sette Silva E.L. 1993. Inventário preliminar das espécies arbóreas das florestas dos arredores de Boa Vista (Roraima) - Uma abordagem fitossociológica. Dissertação de Mestrado, INPA, Universidade Federal do Amazonas, Manaus. 198 p.

Shepard F.P. 1954. Nomenclature based on sand-silt clay ratio. Journal of Sedimentary Research, 24(3):151158.

Simões Filho F.F.L. 2000. Sedimentação lacustre e implicações paleoambientais na região de contato floresta-savana de Roraima durante o Holoceno. Tese de Doutorado, Universidade Federal Fluminense, Niterói, 213 p.

Stuiver M. \& Reimer P.J. 1993. Extended 14C database and revised CALIB radiocarbon calibration program. Radiocarbon, 35(1):215-230.

Suguio K. 2003. Geologia Sedimentar, São Paulo, Edgard Blücher, $400 \mathrm{p}$.

Tardy Y. 1993. Pétrologie des latérites et des sols tropicaux. Paris, Masson, 459 p.

Taylor S.R. \& McLenann S.M. 1985. The continental crust its composition and evolution. Oxford, Blackwell Scientific Publications, 312 p.

Vanzolini P.E. \& Carvalho C.M. 1991. Two sibling and sympatric species of Gymnophtalmus in Roraima, Brazil (Sauria Teiidae). Papéis Avulsos de Zoologia, 37(12):73-226.

Wedepohl K.H. 1995. The composition of the continental crust. Geochimica et Cosmochimica Acta, 59(7):1217-1232.

Manuscrito ID 19964

Recebido em: 23/11/2010

Aprovado em: 28/06/2012 